\title{
Evidence to indicate that maillard reaction products can provide selective antimicrobial activity
}

\author{
Kaiwen Mu, Siyun Wang and David D Kitts* \\ Department of Food, Nutrition and Health, Faculty of Land and Food Systems, The University of British Columbia, Vancouver, Canada
}

\begin{abstract}
The Maillard reaction (MR) is a non-enzymatic browning reaction that occurs between carbonyl and amino groups present in foods that are processed or cooked at high temperatures; the result being a vast number of reaction products, termed Maillard reaction products (MRPs). Whereas initial stages of the reaction produce small molecular weight, colorless products; some being volatile and contributing to odor, extending the reaction with prolonged exposure to heat will result in the $\mathrm{MR}$ reaching final stages and generating high molecular weight products that contribute to color and flavor, important sensory attributes. Many specific MRPs also impart a range of biological properties; the most recently noted being antioxidant capacity and to a comparatively lesser extent antimicrobial activity. The potential antimicrobial activity of MRPs appears to be dependent on the strain of microorganism and internal/external factors that influence the physicochemical reactions occurring between microbe and the MRP, albeit, the mechanism(s) offered by MRPs is somewhat unclear. The objective of this paper is to summarize the evidence that MRPs evoke antimicrobial activity when certain conditions exist in foods that facilitate an inhibitory potential. We review the current knowledge of factors that influence the inhibitory effect of MRPs on microorganism growth and proliferation, proposed mechanisms of antimicrobial properties of MRPs, and discussion of future relevant applications.
\end{abstract}

\section{Introduction}

The Maillard reaction (MR) refers to a non-enzymatic browning reaction that occurs when carbonyl (e.g. reducing sugar) and amino (amino acid, peptide or protein) react in heated foods, producing a complex array of products (MRPs) that generate aroma, flavor and color [1]. These important attributes govern sensory appeal and likely initiated the primary interests of early chemists to study the MR. Formation of MRPs is greatly influenced by a number of factors that include the nature of reactants, $\mathrm{pH}$ of the food system, water activity and the temperature and time interaction [2]. Other factors such as the presence of metal ions (e.g. copper and iron), or sulfites, can either enhance or reduce the yield of MRPs, respectively. A wide range of MRPs formed early in the reaction, (e.g. ketones, aldehydes, dicarbonyls), are followed by generation of more complex, high molecular weight products (e.g. heterocyclic amines, and melanoidins) [3-5] in later stages of the reaction. Collectively these compounds are associated with different sensory, physical and chemical properties [6,7], whereas others impart a range of biological properties that include antioxidant capacity [8-10], anti-inflammatory activity [9-11], anti-hypertensive activity [12], and antimicrobial activity (Table 1). The antioxidant activity of MRP has received considerable attention [13-23] and has been associated with extending the shelf-life of foods by postponing oxidation of food products $[24,25]$. There is some evidence that that antimicrobial properties of MRPs could also contribute to extending shelf-life of food products by inhibiting growth of spoilage-causing organisms [13,26,27,28]. In the example with yeast, (Saccharomyces cerevisiae), it was reported that the active MRP component was furfural, which inhibited glycolysis and also alcohol product, due to inhibitory action on key enzymes, especially the dehydrogenases. Potential of MRPs to inhibit growth of food-borne pathogens has also attracted considerable attention [20,29,30]. Of particular interest is that some conditions employed to generate MRPs exhibiting antioxidant activity also resulted in notable antimicrobial activity [13]. From these and other studies it is important to fully understand the inhibitory effect of Maillard reaction against bacteria and possible mechanism(s) of activity. The objective of this paper is to provide a comprehensive description of the antimicrobial properties of MRPs, related factors that influence the inhibitory effect of MRPs, and demonstrated mechanisms of antimicrobial effect of MRPs.

\section{Reaction scheme and products formed in MR}

In general, food product matrices possess subtle differences in $\mathrm{pH}$ and water activity, which in turn influence the final composition of different MRPs during thermal processing. The diverse range of physical, chemical or biological properties of soluble pre-and final stage melanoidins, or mixtures thereof, which result from varied reaction conditions leads to a cascade of redox reactions that generate a complex mixture of molecules. This represents a major challenge for food scientists to conclude specific structure-function of MRPs with antimicrobial activity. Initiation of the MR is greatest at slightly basic $\mathrm{pH}$, a requirement for the nucleophilic reaction by the amino nitrogen lone-pair electron condensing with a carbonyl carbon on the reducing sugar. The result is the formation of glycosylamine, which dehydrates to a Schiff base and then to Amadori rearrangement. If $\mathrm{pH}$ is acidic, the rearrangement of Amadori to 1,2 enolization is facilitated. This is in contrast to subsequent formation of many different chemical

Correspondence to: David D Kitts, Department of Food, Nutrition and Health, Faculty of Land and Food Systems, The University of British Columbia, Vancouver, V6T-1Z4 B.C, Canada; E-mail: ddkitts@mail.ubc.ca

Keywords: Maillard reaction products, melanoidins, gram positive, gram negative bacteria, iron acquisition

Received: July 03, 2016; Accepted: July 15, 2016; Published: July 18, 2016 
intermediates that otherwise occur if the $\mathrm{pH}$ is basic, and directed through a 2,3- enolization reaction. Dehydration and fragmentation of the sugar molecules along with loss of available amino acids leads to a number of additional pre-melanoidin products formed in the intermediate stage. This in turn ultimately influences the composition of final stage MRPs. Aldol condensation and formation of heterocyclic nitrogenous compounds occurs with simultaneous polymerization of high molecular weight melanoidins. In complex food systems, such as coffee, melanoidins are formed from polymerization reactions of furans and pyrroles derived in part from phenolic acids reacting with amino acids.

\section{Can MRPs replace traditional, chemical antimicrobial agents?}

Presently, antimicrobial agents used by the food industry include organic acids and their salts such as acetic, lactic, propionic, sorbic or benzoic acid, these being favored because of their relatively low cost and high efficacy [31]. In recent years, the use of natural and effective antimicrobial compounds has received considerable attention to replace chemical counterparts. Along with the interest in studying the antioxidant activities offered by MRP [32], other works has examined the potential of using MRPs as antimicrobial agents (Table 1). These two important functional properties may be derived simultaneously, and naturally, during food processing and storage and are considered ubiquitous to the food system in contrast to using alternative food chemical additives. For example, MRPs derived from heated reducing sugar-amino acid model systems have reported affinities that induce bacterial DNA scission, potentially leading to mutation and cytotoxicity $[33,34]$. Hydrogen peroxide formation considered a product of MRP synthesis represents a cytotoxic component [35]. Other works has demonstrated alterations of specific virulence regulators of known food pathogens when in the presence of model MRPs [36]. Accelerated non-enzymatic browning reaction, using a glucosamine $/ \mathrm{Fe}^{2+}$ complex to generate singlet oxygen and reactive alpha dicarbonyls, will lower $\mathrm{MIC}_{50}$ values against heat-resistant E.coli at acidic rather than neutral $\mathrm{pH}$ [30]. High molecular weight $(>10 \mathrm{kDa})$ melanoidins have also been identified as active MRPs with effective antimicrobial activity that have the potential to induce irreversible damage of cell membrane permeability and function $[12,20]$. The antimicrobial properties of MRPs generated in commercial food products such as coffee, beer and biscuit have also been widely investigated $[19,20]$. In coffee brew, in contrast to green coffee extracts, antimicrobial activity was observed towards a wide range of bacteria; Gram-positive bacteria being relatively more sensitive than Gram negative bacterial. Antibacterial activity was not related to the brewing procedure but was consistently apparent to degree of coffee bean roasting [15].

\section{Factors regulating antimicrobial efficacy of MRPs}

The inhibitory effects of MRP against pathogens appears to depend mostly on three primary factors; namely, the species/strain of bacteria; the physical-chemical nature of sugar and amino acid reactants and the external factors that influence the kinetics of Maillard reaction (e.g. temperature and duration, $\mathrm{pH}$ and water content), and by consequence, the specific properties of MRP products formed [37,38]. Antimicrobial activity of MRPs against several microorganisms, including Aeromonas hydrophila, Staphylococcus aureus, Listeria monocytogens [14], Helicobacter pylori [17], Bacillus stearothermophilus [28], Salmonella enterica [14] and Escherichia coli [13] have been reported. The inhibitory effect of MRPs against pathogens by direct exposure to crude

Table 1. Main findings on some studies on Maillard reaction products and their antimicrobial activities.

\begin{tabular}{|c|c|c|c|c|c|}
\hline Year & MRP & Gram (+) bacteria & Gram (-) bacteria & Main findings & Reference \\
\hline 1983 & Arginine-xylose or Glucose-histidine & $\begin{array}{l}\text { Staphylococcus aureus } \\
\text { Bacillus subtilis }\end{array}$ & Escherichia coli & HMW MRPs were more inhibitory than LMW MRPs & {$[13]$} \\
\hline 1991 & Glucose-glycine & $\begin{array}{l}\text { Staphylococcus aureus } \\
\text { Listeria monocytogenes }\end{array}$ & $\begin{array}{l}\text { Salmonella } \\
\text { typhimurium } \\
\text { Salmonella enteritidis } \\
\text { Aeromonas hydrophila }\end{array}$ & $\begin{array}{l}\text { A.hydrophila was strongly inhibited } \\
\text { S.aureus \& L.monocytogenes were slightly inhibited by } \\
\text { high } \mathrm{pH} \\
\text { Salmonella } \text { strains were resistant to MRP }\end{array}$ & {$[14]$} \\
\hline 1994 & Coffee & \begin{tabular}{|l|} 
Staphylococcus aureus \\
Bacillus subtilis \\
Streptococcus pyogenes \\
Streptococcus faecalis
\end{tabular} & $\begin{array}{l}\text { Escherichia coli } \\
\text { Escherichia cloacae } \\
\text { Pseudomonas } \\
\text { aeruginosa } \\
\text { Pseudomonas vulgaris } \\
\text { Salmonella } \\
\text { typhimurium }\end{array}$ & $\begin{array}{l}\text { Gram-negative bacteria were more resistant to coffee } \\
\text { than Gram-positive bacteria, with exception of } S \text {.faecalis }\end{array}$ & {$[15]$} \\
\hline 2002 & Green and roasted coffee & Streptococcus mutan & - & $\begin{array}{l}\text { LMW coffee melanoidins may contributed to } \\
\text { antiadhesive properties of roasted coffee }\end{array}$ & {$[16]$} \\
\hline 2004 & Lactose-casein & - & Helicobacter pylori & H. pylori was strongly inhibited & {$[17]$} \\
\hline 2006 & Coffee, beer \& sweet wine & Staphylococcus aureus & Escherichia coli & $\begin{array}{l}\text { Antimicrobial activity wine }>\text { low roasted coffee }>\text { light } \\
\text { beer }\end{array}$ & {$[18]$} \\
\hline 2008 & $\begin{array}{l}\text { Coffee, beer \& sweet wine } \\
\text { Glucose-alanine, arginine, cysteine, histidine, } \\
\text { lysine, methionine, tyrosine, tryptophan, } \\
\text { phenylalanine }\end{array}$ & Staphylococcus aureus & Escherichia coli & $\begin{array}{l}\text { Gram-negative bacteria were more resistant to coffee } \\
\text { than Gram-positive bacteria }\end{array}$ & {$[19]$} \\
\hline 2008 & Coffee and biscuit & - & Escherichia coli & HMW MRPs exhibit highest inhibitory effect & {$[20]$} \\
\hline 2014 & Ribose-lysine & - & Escherichia coli & MRP inhibit growth & [21] \\
\hline 2015 & Glucose-histidine & & - & MRP- $\mathrm{H}_{2} \mathrm{O}_{2}$ interactions & {$[52]$} \\
\hline 2016 & Half-fin anchovy hydrolysates-glucose conjugates & $\begin{array}{l}\text { Staphylococcus aureus } \\
\text { Bacillus subtili } \\
\text { Bacillus megaterium } \\
\text { Sarcina lutea }\end{array}$ & $\begin{array}{l}\text { Escherichia coli } \\
\text { Pseudomonas } \\
\text { fluorescens } \\
\text { Proteus vulgaris } \\
\text { Pseudomonas } \\
\text { aeruginosa }\end{array}$ & $\begin{array}{l}\text { MRPs exhibited variable antibacterial activities against } \\
\text { different bacteria } \\
\text { Cell integrity was destroyed through membrane } \\
\text { permeabilization }\end{array}$ & [22] \\
\hline
\end{tabular}


MRPs generated from different sugar-amino acids modeling systems, including arginine-xylose, histidine-glucose [13], glucose-glycine [14], glucose-phenylalanine, glucose-lysine, glucose-tryptophan, glucosealanine, and glucose-tyrosine [19] have been reported. Einarsson and co-workers [13] were first to demonstrate that antimicrobial activity of MRPs was dependent on both the type of crude MR product formed and the bacteria involved. Their experiments were conducted using MRPs generated from arginine-xylose or histidine-glucose model systems, and both MRPs were efficient at inhibiting growth of Bacillus subtilis, Escherichia coli and Staphylococcus aureus. In specific examples, growth rates of some strains were unaffected albeit their lag phases were extended. Stecchini and co-workers (1991) demonstrated that unlike A.hydrophila, Salmonella strains were resistant to glucoseglycine MRP products when products were generated at $\mathrm{pH} 6.0$ and 8.8 , thus revealing that subtle differences in MR chemical pathways was a factor. Daglia and co-workers [16] reported that Gram-positive bacteria were relatively more sensitive to MRP derived inhibition, compared to Gram-negative bacteria. Aminoreductone (AR), one of the early-stage Maillard reaction products often demonstrated in MRmodel was a antimicrobial component with activity in methicillinresistant Staphylococcus aureus [40]. Rufián-Henares and Morales [20] observed a significant difference between E.coli (Gram-negative) and S.aureus (Gram-positive) with respect to relative sensitivities to high molecular weight MRPs, products formed in final stage of MR; which was in agreement with a previous study.

Many studies have indicated that relative sensitivity of different species of bacteria to MRPs varies depending on the $\mathrm{pH}$ of the Maillard reaction system. Einarsson and co-workers [39] reported that antimicrobial properties of MRPs were influenced by $\mathrm{pH}$ of the reaction as mentioned above. Stecchini and others [14] further evaluated the effect of MRPs on the growth of Staphylococcus aureus, Listeria monocytogenes, Salmonella typhimurium and Aeromonas hydrophilia, and showed that MRP mixtures produced at $\mathrm{pH}$ of 8.8 extended the lag phase and also inhibited the growth of Aeromonas hydrophilia uniquely to other organisms. Staphylococcus aureus and to a lesser degree Listeria monocytogenes showed an effect on lag phase, and only a small effect on final proliferation; whereas Salmonella typhimurium had no effect on either parameter when exposed to MRPs. Similar effects of MRPs on specific components of the temporal growth patterns were also observed with different microorganism [13], indicating that many bacteria respond differently to different MPRs. In fact, heating fructose and glucose alone in $\mathrm{pH}$ buffers, 5.0 and 7.0 at sterilization temperatures $\left(100^{\circ} \mathrm{C}-120^{\circ} \mathrm{C}\right)$ for up to two hours, has also been reported to produce inhibitory activity against E.coli growth; this observations was not be attributed to furfural or 5-hydroxymethylfurfural content [41]. Taken together these many studies indicate that the complexity of MRP composition, depending on stage of the reaction or chemical pathway that produces either a single or a complex mixture of reactive products in both intermediate and late-stages of the reaction, represents the tremendous challenge to a define a specific structure-antimicrobial activity relationship for one or more MRP.

As a general rule, the temperature and duration of Maillard reaction determines both the yield and the composition of MRPs, thereby influencing both physical and chemical properties of derived products. Previous studies have demonstrated greater inhibitory activity from prolonged heating which trends towards those products formed in the final stages of the reaction. Einarsson and co-workers [13] advocated that a high molecular weight fraction recovered from crude MRP was more efficient at inhibiting bacterial growth when tested with Bacillus subtilis, Escherichia coli and Staphylococcus aureus in comparison to lower molecular weight MR compounds. Similar findings were reported by Ruffian-Henares and Morales [18] with high molecular weight melanoidins derived from coffee, compared with non-covalently melanoidins-linked compounds when tested with [19]. A similar trend occurs for the relative antioxidant capacity observed between high and low molecular weight MRPs when examined for a capacity to scavenging hydroxyl and DPPH radicals in Caco-2 cells [23]. The increase in reducing power noted in different fractions recovered coincided with an increase in browning intensity [32]. Although it is tempting to correlate antimicrobial activity of MRPs with browning intensity, there is evidence to show that low molecular weight compounds bound to melanoidins have higher antimicrobial activity relative to corresponding pure melanoidins [12]. Thus, it appears that melanoidin chromosphores are not totally responsible for antimicrobial activity [12]. Daglia and co-workers [16], evaluated the effect of coffee variety, degree of roasting and differences in brewing procedures on the inhibitory effect of coffee MRPs against both Grampositive and Gram-negative bacteria. The degree of roasting had a significant effect on antibacterial activity of MRPs. This finding agreed with Lanciotti and co-workers [28], who also concluded the inhibitory effect of MRPs was dependent on the degree of browning and related to redox potential. Further evidence for this came from RufiánHenares and Morales [20], who described MRPs generated from dark roasting coffee and dark beer exerted higher antimicrobial activity than corresponding light roasting coffee. Again, others have shown that advanced browning compounds exerted a greater inhibitory effect on Bacillus stearothermophilus, whereas MRPs generated in earlier stages of the MR reduced the length of the lag phase of microorganism growth in comparison to the control [42]. It is highly possible that unreacted sugars and amino acid also represent potential nutrients available for microorganism proliferation which in turn reduce the length of the lag phase, but have no effect on growth rate.

\section{Proposed antimicrobial mechanisms of MRPs}

In general, antimicrobial agents fall into three categories, namely, inorganic, organic, and natural biologicals. The principal antimicrobial mechanisms depend on the antimicrobial agent and include interference with cell wall synthesis or bacterial membrane structure, inhibition of protein synthesis or metabolic pathway and interference with nucleic acid synthesis of action [43]. As naturally formed products, MRPs fall into the category of natural biological antimicrobial agents. A few investigators have postulated the mechanisms of antimicrobial properties of MRPs [18,19].

Iron is an essential nutrient for microorganisms, representing a valued cofactor for many important biochemical reactions that include cell respiration and DNA replication and other important cellular redox processes. In addition to free iron, heme is also a major source for iron used by pathogenic bacteria. Moreover, the bioavailability of iron will affect the proliferative capacity of pathogens because iron is an indispensable cofactor for many enzymes involved in growth [44]. In the host, iron is normally bound to protein, such as the transport protein transferrin, lactoferrin or ferritin, which restricts the accessibility of iron ions by microbes [44]. Nevertheless, the concentration $\left(10^{-}\right.$ ${ }^{18} \mathrm{M}$ ) of the iron that is freely accessible in the host is lower than the optimal iron concentration $\left(10^{-7} \sim 10^{-5} \mathrm{M}\right)$ required for bacterial growth [45]. Therefore, non-heme ferric transport and heme ferrous transport mechanisms are critical for the microorganism to acquire iron. Microbial iron acquisition systems are different between Gram- 
negative and Gram-positive bacteria, which corresponds to a relatively lesser known mechanisms for ionic and heme iron acquisition in Grampositive bacteria. The capacity of Gram-negative bacteria to secrete siderophore in order to bind free iron ions with the formation of an iron- or heme- containing complex is an important component of the acquisition system and one that has not been as clearly demonstrated in Gram-positive bacteria. Gram-negative bacteria have hundreds of high-affinity siderophores to bind free iron. As the size of ironsiderophore complex exceeds the size of porins (size limit of $\sim 600 \mathrm{Da}$ ), a receptor on the outer membranes is required to ferry the complexes for utilization [45]. In addition, TonB-dependent transporters (TBDTs) located on the outer membrane of Gram-negative bacteria enable iron absorption. TBDTs bind to, and transport, ferric chelate complexes with high specificity to the periplasmic space that is mediated by an energy-transducing ExbB-ExbD-TonB system [45]. Subsequently, a substrate-specific periplasmic binding protein transports the iron substrate to an ATP-binding cassette $(\mathrm{ABC})$ transport system, and the $\mathrm{ABC}$ transport system moves the iron into the cytosol [45]. Grampositive bacteria do not possess an outer membrane, thus are devoid of membrane receptors and the ExbB-ExbD-TonB system [44]. Hence iron acquisition mechanisms that may reduce risks attributed to situations of low iron availability provide greater resistance to Gramnegative bacteria that are exposed to low soluble iron. In addition, noted unique differences in iron-dependent regulator mechanisms exist between Gram-negative and Gram-positive bacteria at the genetic level. For example, inactivation of the ferric uptake regulation (fur) gene results in deregulation of iron metabolism, thus increasing the sensitivity to redox stress. This effect can be reversed by iron chelation, thereby reducing the free iron available for metabolism. This may also explain the difference in sensitivity to iron bioavailability between Gram-negative and Gram-positive bacteria [46].

The bioavailability of ferric iron is also a factor, since it is greatly reduced by its naturally low solubility, a function of $\mathrm{pH}$. Low bioavailability of extracellular iron will target the iron acquisition as described above for extracellular pathogens and limit growth potential. Lowering external $\mathrm{pH}$ to increase ferric ion solubility and reducing ferric iron to the more soluble ferrous form can improve iron bioavailability for acquisition. Few investigators have ascribed antimicrobial properties of melanoidins to an iron-binding capacity. Einarsson and others [13] first reported that high molecular weight MRPs had greater antimicrobial activity than corresponding low molecular weight MRPs. This would seem to be a competitive inhibition towards MRP iron sequestering, possibly influenced by $\mathrm{pH}$ of the food matrix, with the iron acquisition mechanism that the organism relies on to utilize ionic iron or heme. Gomyo and Horikoshi [47] reported melanoidins to be anionic hydrophilic polymers, capable of forming stable complexes with metal cations, such as ferric $\left(\mathrm{Fe}^{3+}\right)$ ion. Migo and others [48] further described melanoidins as having a negative net charge at $\mathrm{pH}$ values common to many food matrix $\mathrm{pH}$, enabling effective sequestering of metallic ions. In agreement with previous studies, Ruffian-Henares and Morales [29] also reported that antimicrobial activity of melanoidins was mediated by iron chelation whereby effectively interacting with siderphore- $\mathrm{Fe}^{3+}$ complexes, adversely affected iron acquisition. Moreover the sequestering of available iron by MRPs may also adversely affect the bacterial gene expression for membrane-receptors to bind iron thus reducing the sensitivity towards reduced iron availability. Taken together, the iron binding capacity of melanoidins disturbs the otherwise important binding of iron to siderophores in bacteria [49]. To worsen the situation, it is also likely that high molecular weight $(>10 \mathrm{kD})$ melanoidins have some degree of steric hindrance which could adversely affect the iron- siderophore binding efficiency, or the receptor affinity to bind iron.

Rufian-Henares and Morales [20] observed the inhibitory effect of MRP against S.aureus was significantly higher than, and postulated that the antimicrobial activity of melanoidin was therefore pathogen specific. Mechanisms underlying the antimicrobial activity of melanoidins against were proposed to include interfering with cell integrity and inner- and outer-membrane permeability. These authors postulated that possible antimicrobial mechanisms of MRP on Gram-negative pathogens such as, resulted in irreversible cell membrane damage and associated alterations in mass transfer of important biochemical macromolecular compounds required for biosynthetic reactions. This property could explain the noted differences in sensitivities of Grampositive and Gram-negative microorganisms towards MRPs due to mechanism of iron acquisition.

Another potential mechanism for explaining the antimicrobial activity of MR components involving transition metal ions, such as iron, concerns the association of iron with MRPs to generate alpha dicarbonyls from decomposition of Amadori products [50]. Methylglyoxal (MGO), a degradation product of 3-deoxyglucosone (3-DG) is an effective inhibitor of growth by interfering with DNA and protein synthesis [51]. Notwithstanding this, is the generation of hydrogen peroxide, an antibacterial agent due to its strong oxidizing action is formed during non-enzymatic browning [35]. The antibacterial activity could therefore be provided by the generation of a hydroxyl radical from the Fenton Reaction that involves ferrous ion interacting with hydrogen peroxide. Recently, glucosamine browning in the presence of ferrous ion displayed antimicrobial activity towards heat resistant at $\mathrm{pH} \mathrm{5,} \mathrm{but} \mathrm{not} \mathrm{pH} 7$, thus showing the importance of maintaining ferrous ion solubility to initiate reactivity with nonenzymatic browning precursors that generate alpha dicarbonly and hydrogen peroxide byproducts; candidates for the observed antimicrobial activity [30].

\section{Conclusion and future challenges}

MRPs have received considerable attention over the years as a potential functional food ingredient that can produce antimicrobial activity through the natural process of cooking or thermal processing of foods. The antimicrobial activity of MRPs has been attributed to presence of high molecular weight melanoidins for the most part in both sugar-amino acid models and also in more complex food systems, such as coffee. Nevertheless, the structure-specific effects of melanoidins are yet to be completely elucidated, due to the lacking of purification, identification and quantification methods/data that will enable clear structural information of melanoidins. The parallel advances in understanding iron metabolism in both Gram-negative and Gram-positive bacteria, along with advancing knowledge on ways to enhance iron sequestering activity of MRPs could lead to interesting studies that will result in knowing what conditions are required for specific, tailor made, MRPs. These MRPs would not only have high binding activity towards iron, but also the necessary qualities for steric hindrance to mitigate bacterial iron acquisition. Further evaluation on other health aspects, such as dental care and the association of MRPs with Streptococcus mutans warrants investigation [52]. On the other hand, we should not forget that the physical-chemical attributes of MRPs useful to inhibit food spoilage and pathogenic bacteria growth and proliferation could also have adverse effects on those good bacteria that provide a healthy human large-bowel micro biome [52]. 


\section{References}

1. Farmer LJ, Mottram DS, Whitfield FB (1989) Volatile compounds produced in Maillard reactions involving cysteine, ribose and phospholipid. J Sci Food Agri 49: 347-368.

2. Wijewickreme A, Kitts DD (1997) Influence of reaction conditions on the oxidative behavior of model Maillard reaction products. J Agric Food Chem 45: 4571-4576.

3. Wasseriwan AE (1979) Symposium on meat flavor chemical basis for meat flavor: a review. J Food Sci 44: 6-11.

4. Waller G, Feather M (1983) The Maillard reaction in foods and nutrition. Washington, D.C.: American Chemical Society.

5. Izzo HV, Ho C (1992) Peptide-specific Maillard reaction products: A new pathway for flavor chemistry. Trends Food Sci Tech 3: 253-257.

6. Ogasawara M, Katsumata T, Egi M (2006) Taste properties of Maillard-reaction products prepared from 1000 to 5000Da peptide. Food Chem 99: 600-604

7. Sun W, Zhao M, Cui C, Zhao Q, Yang B (2010) Effect of Maillard reaction products derived from the hydrolysate of mechanically deboned chicken residue on the antioxidant, textural and sensory properties of Cantonese sausages. Meat Sci 86: 276282.

8. Chen X, Kitts DD (2008) Antioxidant activity and chemical properties of crude and fractionated maillard reaction products derived from four sugar-amino acid Maillard reaction model systems. Ann N Y Acad Sci 1126: 220-224.

9. Chen XM, Kitts DD (2011) Antioxidant and anti-inflammatory activities of Maillard reaction products isolated from sugar-amino acid model systems. J Agric Food Chem 59: 11294-11303. [Crossref]

10. Chen XM, Kitts DD (2012) Characterization of antioxidant and anti-inflammatory activities of bioactive fractions recovered from a glucose-lysine Maillard reaction model system. Mol Cell Biochem 364: 147-157. [Crossref]

11. Kitts DD, Chen XM, Jing H (2012) Demonstration of antioxidant and anti-inflammatory bioactivities from sugar-amino acid Maillard reaction products. J Agric Food Chem 60: 6718-6727. [Crossref]

12. Rufián-Henares JA, Morales FJ (2007) Functional properties of melanoidins: In vitro antioxidant, antimicrobial and antihypertensive activities. Food Res Int 40: 995-1002.

13. Einarsson H, Snygg BG, Eriksson C (1983) Inhibition of bacterial growth by Maillard reaction products. J Agric Food Chem 31: 1043-1047.

14. Stecchini M, Giavedoni P, Sarais I, Lerici C (1991) Effect of Maillard reaction products on the growth of selected food-poisoning micro-organisms. Lett Appl Microbiol 13: 93-96.

15. Daglia M, Cuzzoni MT, Dacarro C (1994) Antibacterial activity of coffee. J Food Sci 42: $2270-2272$.

16. Daglia M, Tarsi R, Papetti A, Grisoli P, Dacarro C, Pruzzo C, Gazzani G (2002) Antiadhesive effect of green and roasted coffee on streptococcus mutans' adhesive properties on saliva-coated hydroxyapatite beads. J Agric Food Chem 50: 1225-1229.

17. Hiramoto S, Itoh K, Shizuuchi S, Kawachi Y, Morishita Y, Nagase M, et al. (2004) Melanoidin, a food protein-derived advanced Maillard reaction product, suppresses Helicobacter pylori in vitro and in vivo. Helicobacter 9: 429-435.

18. Rufián-Henares JA, Morales FJ (2006) A new application of a commercial microtiter plate-based assay for assessing the antimicrobial activity of Maillard reaction products. Food Res Int 39: 33-39.

19. Rufián-Henares JA, Morales FJ (2008) Microtiter plate-based assay for screening antimicrobial activity of melanoidins against E. coli and S. aureus. Food Chem 111: 1069-1074.

20. Rurián-Henares JA, Morales FJ (2008) Antimicrobial activity of melanoidins against Escherichia coli is mediated by a membrane-damage mechanism. $J$ Agric Food Chem 56: 2357-2362. [Crossref]

21. Hauser C, Müller U, Sauer T, Augner K, Pischetsrieder M (2014) Maillard reaction products as antimicrobial components for packaging films. Food Chem 145: 608-613. [Crossref]

22. Song R, Yang P, Wei R, Ruan G (2016) Antioxidative, antibacterial, and food functional properties of the half-fin anchovy hydrolysates-glucose conjugated formed via Maillard Reaction. Molecules 21:795. [Crossref]

23. Jing H, Kitts DD (2004) Antioxidant activity of sugar-lysine Maillard reaction products in cell free and cell culture systems. Arch Biochem Biophys 429: 154-163. [Crossref]
24. Bedinghaus AJ, Ockerman HW (1995) Antioxidative maillard reaction products from reducing sugars and free amino acids in cooked ground pork patties. J Food Sci 60 : 992-995.

25. Lerici CR, Nicoli MC (1996) Chemical and physicochemical properties affecting the quality and stability of bakery products. Adv in Food Sci 18: 229-233.

26. Banerjee N, Bhatnagar R, Viswanathan L (1981) Inhibition of glycolysis by furfural in Saccharomyces cerevisiae. Appl Microbiol Biotechnol 11: 226-228.

27. Lee G-D, Kim J-S, Kwon J-H (1997) Effect of Maillard reaction products on growth of Bacillus sp. Korean J Food Sci Technol 29: 309-313.

28. Lanciotti R, Anese M, Sinigaglia M, Severini C, Massini R (1999) Effects of heated glucose-fructose-glutamic acid solutions on the growth of Bacillus stearothermophilus. LWT - Food Sci Technol 32: 223-230.

29. Rufián-Henares JA, de la Cueva SP (2009) Antimicrobial activity of coffee melanoidins-a study of their metal-chelating properties. J Agric Food Chem 57: 432 438. [Crossref]

30. Hrynets Y, Bhattacherjee A, Ndagijimana M, Hincapie Martinez DJ, Betti M (2016) Iron $(\mathrm{Fe}(2+))$-catalyzed glucosamine browning at $50^{\circ} \mathrm{C}$ : Identification and quantification of major flavor compounds for antibacterial activity. J Agric Food Chem 64: 3266-3275. [Crossref]

31. Lucera A, Costa C, Conte A, Del Nobile MA (2012) Food applications of natural antimicrobial compounds. Front Microbiol 3: 287. [Crossref]

32. Wang H, Qian H, Yao W (2011) Melanoidins produced by the Maillard reaction: Structure and biological activity. Food Chem 128: 573-584.

33. Kitts DD, Wu CH, Stich H, Powrie WD (1993) Effect of glucose-lysine Maillard reaction products on bacterial and mammalian cell mutagenesis. $J$ Agric Food Chem 41: 2353-2358

34. Hiramoto K, Sekiguchi K, Asoo R, Ayuha K, Niyama H, Kato K, Kidugawa K (1995) DNA strand breaks induced through active oxygen radicals by fragrant componen 4-hydroxy-2-hydroxymethl-5-methyl-3(2)-franone in Maillard reaction of hexose amino acids. Food Chem Toxicol 33: 803-814.

35. Hegele J, Münch G, Pischetsrieder M (2009) Identification of hydrogen peroxide as a major cytotoxic component in Maillard reaction mixtures and coffee. Mol Nutr Food Res 53: 760-769. [Crossref]

36. Díaz IB, Chalova VI, O’Bryan CA, Crandall PG, Ricke SC (2010) Effect of soluble maillard reaction products on cadA expression in Salmonella typhimurium. J Environ Sci Health B 45: 162-166. [Crossref]

37. Martins SI, Jongen WM, Boekel MA (2000) A review of Maillard reaction in food and implications to kinetic modelling. Trends Food Sci Tech 11: 364-373.

38. Jousse F, Jongen T, Agterof W, Russell S, Braat P (2002) Simplified kinetic scheme of flavor formation by the Maillard reaction. J Food Sci 67: 2534-2542.

39. Einarsson H, Snygg BG, Eriksson C (1987) The effect of time, temperature, $\mathrm{pH}$ and reactants on the formation of antibacterial compounds in the Maillard reaction. LEBENSM WISS TECHNOL 20: 51-55.

40. Trang VT, Takeuchi H, Kudo H, Katsuno S, Shimamura T, Kashiwagi T, et al. (2011) In vitro antimicrobial activity of aminoreductone against the pathogenic bacteria Methicillin-Resistant Staphylococcus aureus (MRSA). J Agric Food Chem 59: 89538960.

41. Skkuortti T, Maikki Y (1984) Antimicrobial activities of heated glucose and fructose solutions and their elucidation by high pressure liquid chromatography. Food Chem 15: $165-173$.

42. Lertittikul W, Benjakul S and Tanaka M (2007) Characteristics and antioxidative activity of Maillard reaction products from a porcine plasma protein-glucose mode system as influenced by pH. Food Chem 100: 669-677.

43. Tenover FC (2006) Mechanisms of antimicrobial resistance in bacteria. Am J Med 119 S3-10. [Crossref]

44. Parrow NL, Fleming RE, Minnick MF (2013) Sequestration and scavenging of iron in infection. Infect Immun 81: 3503-3514. [Crossref]

45. Andrews SC, Robinson AK, Rodríguez-Quiñones F (2003) Bacterial iron homeostasis. FEMS Microbiol Rev 27: 215-237. [Crossref]

46. Massé E, Gottesman S (2002) A small RNA regulates the expression of genes involved in iron metabolism in Escherichia coli. Proc Natl Acad Sci USA 99: 4620-4625. [Crossref] 
Mu K (2016) Evidence to indicate that maillard reaction products can provide selective antimicrobial activity

47. Gomyo T, Horikoshi M (1976) On the Interaction of Melanoidin with Metallic Ions. Agric Biol Chem 40: 33-40.

48. Migo VP, Rosario EJ, Matsumura M (1997) Flocculation of melanoidins induced by inorganic ions. Journal of Fermentation and Bioeng 83: 287-291.

49. Morales F (2005) Iron-binding ability of melanoidins from food and model systems? Food Chem 90: 821-827.

50. Hayase F, Shibuya T, Sato J, Yamamoto M (1996) Effects of oxygen and transition metals on the advanced Maillard reaction of proteins with glucose. Biosci Biotechnol Biochem 60: 1820-1825. [Crossref]
51. Fraval HN, McBrien DC (1980) The effect of methyl glyoxal on cell division and the synthesis of protein and DNA in synchronous and asynchronous cultures of Escherichia coli B/r. J Gen Microbiol 117: 127-134. [Crossref]

52. Mizuno M, Inoue K (2015) Synergic antimicrobial effect between Maillard reaction product (MP) and hydrogen peroxide $\left(\mathrm{H}_{2} \mathrm{O}_{2}\right)$ on Steptococcus mutans. Journal of Restor Dent 3: 64-69.

53. Ames JM, Wynne A, Hofmann A, Plos S, Gibson GR (1999) The effect of a model melanoidin mixture on faecal bacterial populations in vitro. Br J Nutr 82: 489-495. [Crossref]

Copyright: (C2016 Mu K. This is an open-access article distributed under the terms of the Creative Commons Attribution License, which permits unrestricted use, distribution, and reproduction in any medium, provided the original author and source are credited. 